\title{
○ิ Discurso pronunciado por el profesor José Morandé Lavín en el acto de investidura de su segundo período como director del IEI
}

\section{Santiago, 11 de agosto de 2010}

Mi gratitud y reconocimiento a toda la comunidad del Instituto de Estudios Internacionales por su valiosa colaboración a la gestión institucional y académica. Asimismo, agradezco la confianza depositada en esta dirección al renovarle un nuevo periodo la conducción de nuestro Instituto.

Expreso también mi reconocimiento a los profesores, personal de colaboración y estudiantes por asumir y compartir en forma creciente el compromiso universitario y la valoración entusiasta y comprometida del trabajo en equipo.

Hace cuatro años y conforme a la identidad, trayectoria y carácter único de este Instituto en el país, invitamos a los miembros de nuestra comunidad a una tarea conjunta de renovación y responsabilidad compartida, sustentada en los valores más trascendentes de la Universidad de Chile. En otras palabras, teniendo como norte la excelencia académica, apostamos por los principios de la libertad, el pluralismo y la tolerancia en el campo de las ideas y creencias, a partir del diálogo intelectual así como del más estricto respeto interpersonal. En este clima de confianzas iniciamos el desarrollo de comunidades epistémicas interdisciplinarias y universitarias 
conforme a criterios de relevancia académica y de acción en nuestros compromisos con el medio externo.

En el marco de nuestro Proyecto de Desarrollo Institucional y coincidiendo con el PDI de la Universidad de Chile, nos propusimos la reinserción del Instituto en el medio nacional e internacional, entendido como un referente en los estudios internacionales en Chile y de Chile en América Latina.

A partir de lo anterior y de acuerdo con la naturaleza, tradición y proyección interdisciplinaria de nuestro Instituto, el desarrollo temático de la política exterior -como objeto y sujeto de estudio- constituye un eje articulador y concurrente de diferentes enfoques disciplinares en un área de conocimiento relevante y de acción prioritaria para el IEI.

Es así como hemos definido la política exterior en el ámbito de las políticas públicas internacionales, identificándola como una de las líneas centrales de trabajo y proyección académica del Instituto. De esta forma, consideramos aquellos procesos dinámicos que operan entre actores e instituciones estatales y de otra naturaleza; desde sus dimensiones internas y externas que influyen en los procesos decisionales de los gobiernos en un contexto de globalización del sistema internacional contemporáneo.

Una de las expresiones de esta estrategia y plan de desarrollo universitario es nuestra opción por la docencia, que ha sido uno de los principales desafíos para plasmar el quehacer académico institucional e incrementar la formación de nuevos alumnos de modo de acercarnos a las exigencias de la sociedad.

La creación y expansión de Diplomas de Postítulo en estos años, junto con contribuir al cumplimiento de objetivos y planes docentes, han permitido generar un provechoso intercambio de ideas, conocimientos y experiencias entre nuestros académicos y profesionales que representan al mundo público y privado.

En el futuro, nos proponemos acrecentar y consolidar el espacio arduamente ganado en este campo, así como originar nuevos proyectos docentes que den respuesta a las necesidades de los sectores del medio nacional e internacional.

Por su parte, la docencia de postgrado constituye una de las prioridades académicas que hemos apoyado y por la que estamos apostando preferentemente. De esta manera, además 
de estar finalizando el proceso de reacreditación del programa de Magister en Estudios Internacionales con la Comisión Nacional de Acreditación (CNA) hemos presentado para su aprobación ante la autoridad superior la creación de un nuevo Magister en Estrategia Internacional y Política Comercial. Así estamos atendiendo la demanda de nuevas competencias profesionales en el ámbito de los estudios internacionales y con el apoyo de universidades y organismos extranjeros.

Desde la perspectiva de la investigación y la cooperación internacional, la trayectoria del Instituto ha permitido fortalecer y desarrollar vínculos con entidades académicas y gubernamentales a fin de generar nuevos conocimientos en materia internacional.

Además del trabajo en las líneas tradicionales de la investigación a través de Fondecyt y proyectos de la Vicerrectoría de Investigación y Desarrollo, nuestro interés también se ha manifestado en lograr una valoración de la investigación aplicada, esto es, la generación de respuestas a problemas concretos y propuestas de alternativas especificas de acción. Es así como, entre otros proyectos hemos acogido y estamos impulsando iniciativas en proyectos de opinión pública y política exterior en colaboración con el CIDE de México, generación de diálogo entre Chile y Perú con la Fundación Adenauer y la Pontificia Universidad Católica de Perú y la Cátedra OMC.

La cooperación internacional es una tarea a partir de la cual estamos optando para proyectarnos y crecer con nuestro Plan de Desarrollo Institucional y Docente, reforzando equipos de investigación y potenciando pasantías e intercambio de académicos y estudiantes con redes y universidades extranjeras.

En las redes de cooperación académica estamos operando y proyectando iniciativas y proyectos con centros europeos y latinoamericanos. Entre las primeras instituciones destacan el proyecto de la Cátedra OMC y la participación de la Unctad, la Universidad Autónoma de Madrid y la Universidad Técnica de Berlín. Asimismo, operamos con instituciones de cooperación transcontinental, como el Observatorio de las Relaciones de Europa y América Latina (Obreal). En el campo más específicamente regional, estamos desarrollado vínculos y realizando tareas conjuntas con redes latinoamericanas de universidades mexicanas, brasileñas, colombianas, argentinas, peruanas y de 
otros centros de la región. Al respecto, cabe destacar opinión pública y política exterior latinoamericanas organizada por el CIDE de México.

En materia de convenios de desarrollo y cooperación internacional estamos iniciando la suscripción de acuerdos de intercambio académico con el Instituto de Estudios Latinoamericanos de la Universidad de Ankara-Turquía; la Escuela de Diplomacia y Estudios Internacionales de África del Este de la Universidad de los Mártires de Uganda y reactivando nuestros vínculos con la Escuela de Estudios Internacionales de la Universidad de Denver.

Por cierto, junto con constituir una gran oportunidad de desarrollo institucional, esta cooperación nos exige mayores tareas y muchas veces nos vemos sobrepasados por ofertas de colaboración. No obstante, la cooperación nos abre perspectivas reales y muy valiosas para un verdadero desarrollo académico de excelencia.

Las tareas de extensión y vínculos con el medio las concentramos en tareas específicas de nuestros académicos, con participación en entrevistas especializadas de prensa escrita, radio y televisión, en temas y materias atingentes a los estudios del Instituto.

Por su parte, la revista Estudios Internacionales, con una notable trayectoria de más de cuarenta años, sigue aportando a la difusión de materias internacionales y latinoamericanas y constituye un instrumento fundamental de nuestra conexión al mundo. Para atender a la necesidad de contar con estándares de validación y calidad a nivel nacional e internacional de la revista, estamos concluyendo el proceso de indexación a través de SciELO.

En otro ámbito, igualmente importante para la conexión con el medio, ha sido la implementación del sitio web del Instituto. Esta iniciativa, que ha crecido junto a nuestra propuesta, ha venido reflejando los resultados del trabajo académico y ofrece hacia el futuro una comunicación dinámica, pluralista y de calidad y presencia a nivel domestico e internacional. 


\section{¿Cómo trabajar en la Universidad de hoy?}

Durante la gestión de estos últimos años, hemos tenido que vivir con los cambios y exigencias experimentados por la Universidad de Chile. Así, hemos debido aprender y adecuarnos a esta exigente realidad, explorando y desarrollando nuestro potencial en nuevos y desafiantes ámbitos para la gestión de recursos humanos y económicos.

Transitando hacia un modelo de gestión académica acorde con los tiempos y desafíos actuales y teniendo presente la necesidad de hacer crecer y proyectar al Instituto hacia nuevos horizontes, requerimos el compromiso diario de los académicos así como el apoyo de personal calificado con mayores niveles de excelencia, eficiencia y transparencia en la gestión.

Lo anterior es posible y contamos con los recursos humanos y de equipamiento como para llevar adelante esta tarea. El patrimonio académico a nivel nacional e internacional que representa el equipamiento y eficiente funcionamiento de la biblioteca del Instituto, constituye también un valioso e indispensable aporte académico y profesional al logro de los propósitos de desarrollo institucional.

Para el logro de nuestras metas es esencial una tarea común $y$ de equipo. Sin embargo, quisiera previamente reiterar mis agradecimientos a toda la comunidad del Instituto por las ya alcanzadas durante mi última gestión.

Agradezco también a la Universidad de Chile que nos cobija y estimula, y nos ofrece grandes oportunidades y desafíos. A sus autoridades, en particular al Sr. Rector por su permanente reconocimiento a nuestras actividades y por haber destacado en forma elocuente la calidad especial y la particularidad del Instituto en la Universidad de Chile.

Por último, mi agradecimiento personal por la oportunidad que se me brinda una vez más de poder encabezar una tarea conjunta y compartida entre toda la comunidad del IEI de renovación y consolidación de un proyecto de desarrollo de nuestro Instituto y de la propia Universidad de Chile. 